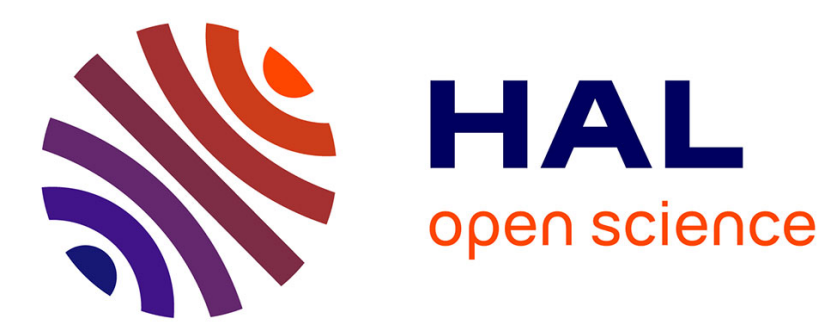

\title{
Influence of Si3N4 interface chemistry on both grain morphology and fracture resistance
}

\author{
H.-J. Kleebe, E. Meissner, G. Ziegler
}

\section{To cite this version:}

H.-J. Kleebe, E. Meissner, G. Ziegler. Influence of Si3N4 interface chemistry on both grain morphology and fracture resistance. Journal de Physique IV Proceedings, 1993, 03 (C7), pp.C7-1393-C7-1397. 10.1051/jp4:19937213 . jpa-00251848

\section{HAL Id: jpa-00251848 https://hal.science/jpa-00251848}

Submitted on 1 Jan 1993

HAL is a multi-disciplinary open access archive for the deposit and dissemination of scientific research documents, whether they are published or not. The documents may come from teaching and research institutions in France or abroad, or from public or private research centers.
L'archive ouverte pluridisciplinaire HAL, est destinée au dépôt et à la diffusion de documents scientifiques de niveau recherche, publiés ou non, émanant des établissements d'enseignement et de recherche français ou étrangers, des laboratoires publics ou privés. 


\title{
Influence of $\mathrm{Si}_{3} \mathrm{~N}_{4}$ interface chemistry on both grain morphology and fracture resistance
}

\author{
H.-J. KLEEBE, E. MEISSNER and G. ZIEGLER
}

University of Bayreuth, Institute of Materials Research (IMA), Postfach 10 12 51, 95440 Bayreuth, Germany

\begin{abstract}
Quantitative microstructural analysis was performed on $\mathrm{Si}_{3} \mathrm{~N}_{4}$ materials doped with $5 \mathrm{wt} \% \mathrm{Y}_{2} \mathrm{O}_{3}$ and $5 \mathrm{wt} \% \mathrm{Sc}_{2} \mathrm{O}_{3}$ as sintering aids. Two different processing routes were utilized to achieve complete densification: (i) gas-pressure sintering of $\mathrm{Si}_{3} \mathrm{~N}_{4}$-starting powders (SSN) and (ii) post-sintering of reaction-bonded $\mathrm{Si}_{3} \mathrm{~N}_{4}$ (SRBSN). Apart from quantitative evaluation of grain diameter and aspect ratio of the matrix grains, the fracture toughness was determined. While the two $\mathrm{Y}_{2} \mathrm{O}_{3}$-doped materials (SSN, SRBSN) showed identical $\mathrm{K}_{\mathrm{IC}}$-values, a large discrepancy in fracture toughness was found for the $\mathrm{Sc}_{2} \mathrm{O}_{3}$-doped $\mathrm{Si}_{3} \mathrm{~N}_{4}\left(\Delta \mathrm{K}_{\mathrm{IC}}=5 \mathrm{MPa} \sqrt{\mathrm{m}}\right)$. SEM crack propagation studies and additional TEM interface characterization showed no significant difference between these materials. Quantitative microstructure analysis, however, revealed a pronounced variation in grain diameter and aspect ratio after thermal treatment. A correlation between interface chemistry and both resulting microstructure and fracture resistance is discussed.
\end{abstract}

\section{Introduction}

Owing to their given brittleness, e.g. low fracture toughness, most oxide- and non-oxide ceramics are strongly limited concerning their potential application in engineering. However, one of the recent and most interesting developments in $\mathrm{Si}_{3} \mathrm{~N}_{4}$-based ceramics is the possibility to grow large $\mathrm{Si}_{3} \mathrm{~N}_{4}$-grains, embedded in a fine grained $\mathrm{Si}_{3} \mathrm{~N}_{4}$-matrix, in-situ. ${ }^{1-3}$ This can results in an improved fracture resistance up to a factor of $2-3 x .^{4}$ Hence, a number of research activities focussed on the study of exaggerated grain growth in these in-situ reinforced ceramics. Different possible contributions to the observed increase in fracture toughness such as grain diameter, aspect ratio, and influence of crystalline secondary phases are still under discussion. It is thought that fracture toughness of monolithic ceramics is mainly governed by grain morphology. Both increased grain diameter and high aspect ratio can affect active toughening mechanisms such as (i) crack deflection and (ii) crack bridging. ${ }^{5-7}$ Moreover, interface structure and chemistry can affect crack propagation (transgranular or intergranular fracture mode). 4,10

In this study we report on quantitative microstructural analysis combined with in-situ dilatometry, scanning and transmission electron microscopy. This combined effort seemingly showed that the aspect ratio of the lage $\mathrm{Si}_{3} \mathrm{~N}_{4}$-grains is the dominating morphological parameter and, in addition, that concerning microstructural development the interface chemistry has to be considered. 


\section{Experimantal Procedure}

The p,T,t conditions during densification were different for both material groups (SSN and SRBSN). The SSN materials underwent a two-step gas-pressure sintering cycle: $1875^{\circ} \mathrm{C}, 5 \mathrm{bar}$ $\mathrm{N}_{2}$-pressure and $1925^{\circ} \mathrm{C}, 100$ bar $\mathrm{N}_{2}$-pressure for $90 \mathrm{~min}$ total, followed by subsequent heat treatment at $1850^{\circ} \mathrm{C}$ for $8 \mathrm{hrs}$. The SRBSN materials were obtained by gas-pressure sintering of reaction-bonded $\mathrm{Si}_{3} \mathrm{~N}_{4}$ at $1875^{\circ} \mathrm{C}, 90 \mathrm{~min}, 5$ bar $\mathrm{N}_{2}$-pressure and $1925^{\circ} \mathrm{C}, 60 \mathrm{~min}, 100 \mathrm{bar} \mathrm{N}_{2}$ overpressure. It should be noted that the SSN materials were held at temperatures above $1800^{\circ} \mathrm{C}$ for a prolonged time (subsequent heat treatment) compared to the SRBSN grades. In-situ dilatometry was performed during densification of the SSN materials registering both linear shrinkage and densification rate. Quantitative microstructural analysis was performed by utilizing a Quantimet 500 image processing system on polished and subsequent $\mathrm{CF}_{4}$-plasma-etched cross sections. ${ }^{8}$ The $\mathrm{K}_{\mathrm{IC}}$-values of the SSN materials were measured by Vickers hardness indentation method $(10 \mathrm{~kg}, 10 \mathrm{~s}, 0.5 \mathrm{~mm} / \mathrm{min})$, whereas the SRBSN materials were characterized by Chevron notch experiments. In addition, crack propagation mode was studied by SEM, and amorphous grain-boundary films were characterized by transmission (TEM) and analytical electron microscopy (AEM).

\section{Results and Discussion}

\subsection{In-situ dilatometry}

Influence of additive composition on densification behavior was monitored by in-situ dilatometry. In general, the addition of $\mathrm{Y}_{2} \mathrm{O}_{3}$ or $\mathrm{Sc}_{2} \mathrm{O}_{3}$ showed the same overall densification behaviour, as depicted in Figure 1. Both densification curves reveal two main maxima, with the first maximum having the highest densification rate. All materials showed nearly complete densification after sintering. However, two major differences concerning densification have to be emphasized: (i) the onset-temperature of densification is lower for $\mathrm{Sc}_{2} \mathrm{O}_{3}$ addition, while (ii) the densification rate (first maximum) is much higher compared to the $\mathrm{Y}_{2} \mathrm{O}_{3}$-doped material (compare Figure 1).

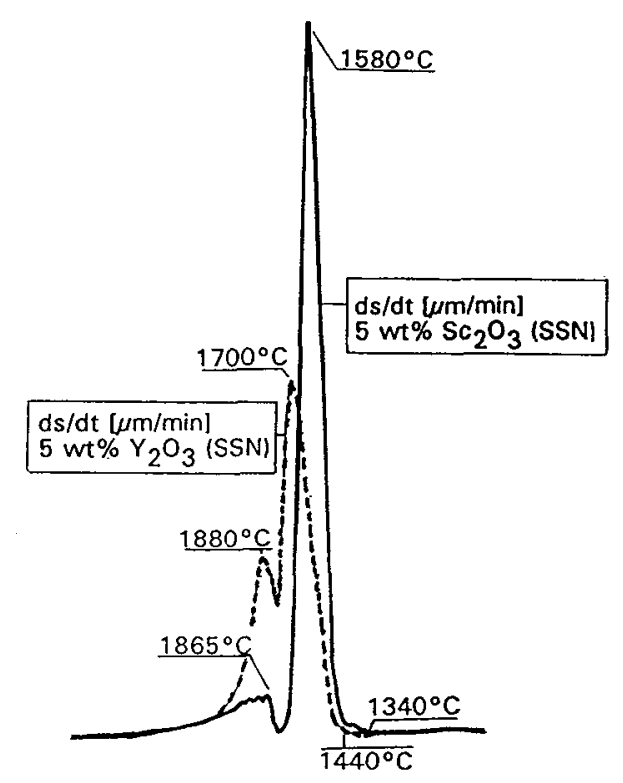

Fig. 1 ds/dt-curves monitored by in-situ dilatometry during densification of $5 \mathrm{wt} \% \mathrm{Sc}_{2} \mathrm{O}_{3}$ and $5 \mathrm{wt} \% \mathrm{Y}_{2} \mathrm{O}_{3}$-doped SSN.
The observed onset-temperatures during densification can be correlated with the liquidus temperatures of the corresponding binary phase diagrams, in particular, with the eutectic temperatures of the systems. The large difference in densification-rate, however, is related to secondary phase composition. The $\mathrm{Sc}_{2} \mathrm{O}_{3}$ addition results in the formation of a liquid phase, which reveals lower viscosity compared to $\mathrm{Y}_{2} \mathrm{O}_{3}$ addition. ${ }^{9}$ Thus, densification proceeds much faster in the $\mathrm{Sc}_{2} \mathrm{O}_{3}$-doped system, although the resulting total volume fraction of residual glass is similar for all four materials (approximately 15 vol\%), which was verified by quantitative image analysis. From dilatometry measurements it can be concluded that densification-rate is mainly governed by additive composition and interface chemistry (identical glass-volume fractions). 


\subsection{Interface characterization by SEM and TEM}

SEM observations of radial cracks, initiated by Vickers indents on polished surfaces, revealed no significant difference concerning fracture mode. All materials showed, independent of additive composition, intergranular fracture (see Figure 2), with the only exception of elongated $\mathrm{Si}_{3} \mathrm{~N}_{4}$ grains being perpenticular to the crack-propagation direction.

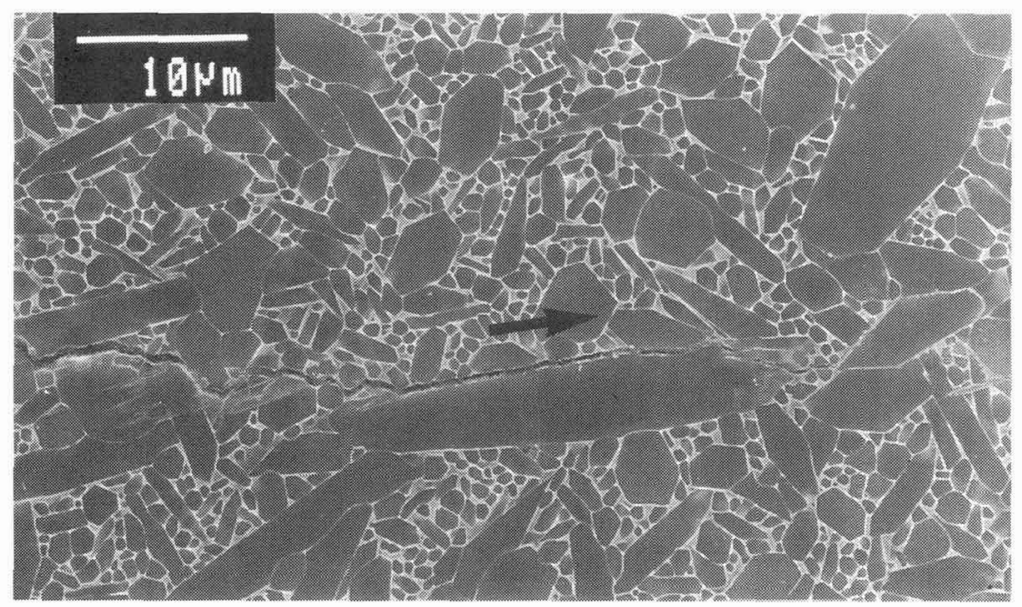

Fig. 2 SEM micrograph of a propagated crack in SSN doped with 5 wt\% $\mathrm{Y}_{2} \mathrm{O}_{3}$.

This indicates that the 'weak link' during crack propagation are grain- and phase boundaries. Interface bonding must be relatively weak in order to support enhanced debonding along grain boundaries. Hence, it is thought that both interface structure and interface chemistry strongly affect crack propagation. High-resolution electron microscopy (HREM) studies on the interface structure in these materials showed a continous grain-boundary film covering all $\mathrm{Si}_{3} \mathrm{~N}_{4}$-grains. ${ }^{10}$ The width of the amorphous intergranular films was about $1.0-1.5 \mathrm{~nm}$ for all materials investigated. In addition, analytical electron microscopy (AEM) studies revealed the presence of addtive cations at the interface (for both dopants). Moreover, excess $\mathrm{O}$ and $\mathrm{N}$ was determined at all grain boundaries analysed. It is concluded, that crack propagation (interface debonding) is simular for all materials studied, although small variations in grain-boundary film thickness and interface chemistry were observed. Hence, the presence of a continuous amorphous interphase along phase- and grain boundaries gives no direct contribution to the resulting fracture toughness, however, it supports debonding to occur along grain boundaries and, therefore, indirectly determines fracture mode and effective toughening mechanism. ${ }^{4}$

\subsection{Quantitative microstructure analysis}

The distributions of grain diameter and aspect ratio were evaluated quantitatively for each material. $\mathrm{Y}_{2} \mathrm{O}_{3}$ containing materials (SSN and SRBSN) showed no significant difference concerning grain-diameter and aspect-ratio distribution. Moreover, identical fracture toughness data $(9 \mathrm{MPa} \sqrt{\mathrm{m}})$ were evaluated for both materials. Microstructural development of the $\mathrm{Sc}_{2} \mathrm{O}_{3}$ doped $S R B S N$ material was also found to be nearly identical to the $\mathrm{Y}_{2} \mathrm{O}_{3}$-doped materials (see Figure 3). This is consistent with the $\mathrm{K}_{\mathrm{IC}}$-value determined (11 MPa $\sqrt{\mathrm{m}}$ ), which is again simular to yttria-doping. The results presented thus far would seemingly suggest that microstructure development (and resulting fracture toughness) is independent of additive composition $\left(\mathrm{Y}_{2} \mathrm{O}_{3}\right.$ or $\mathrm{Sc}_{2} \mathrm{O}_{3}$ ) and processing route (SSN or SRBSN). 
However, it should be noted that the $\mathrm{Sc}_{2} \mathrm{O}_{3}$-containing $\mathrm{SSN}$ material showed a completely different grain-diameter distribution and, in addition, a large difference in aspect-ratio distribution of the large grain fraction $>2 \mu$ grain diameter (see Figures 3 and 4).

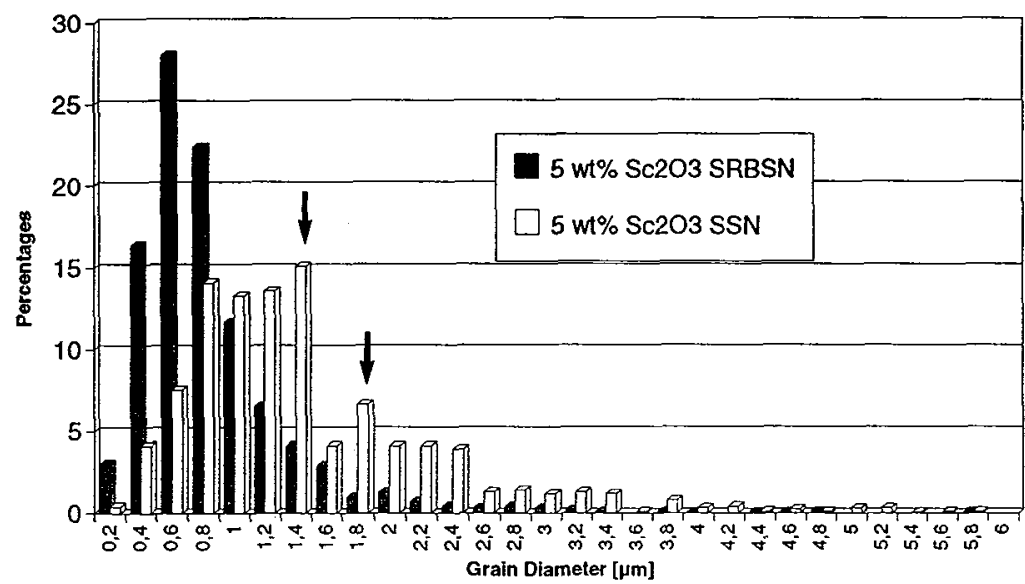

Fig. 3 Grain-diameter distributions of SSN and SRBSN doped with 5wt\% $\mathrm{Sc}_{2} \mathrm{O}_{3}$.

The addition of $5 \mathrm{wt} \% \mathrm{Sc}_{2} \mathrm{O}_{3}$ (SSN) resulted in a microstructure characterized by a shift of the mean grain diameter to higher values (see Figure 3). Moreover, the distribution is, in general, broader compared to the other SSN and SRBSN materials. It is thought that globularization occured during heat treatment and hence, resulted in the reduction of fracture resistance of about $50 \%$ (compared to the equivalent SRBSN material, $\Delta \mathrm{K}_{\mathrm{IC}}=5 \mathrm{MPa} \sqrt{\mathrm{m}}$ ). The results are consistent with dilatometry measurements which show that densification proceeds faster (due to lower viscosity of the liquid) in materials with $\mathrm{Sc}_{2} \mathrm{O}_{3}$ addition. This indicates that kinetic effects can strongly affect the grain-morphology development. In case of lower densification rates, as observed for $\mathrm{Y}_{2} \mathrm{O}_{3}$ addition, the diffusion controlled processes are significantly slower. Thus, retardation of material transport during heat treatment hinders major microstructural changes.

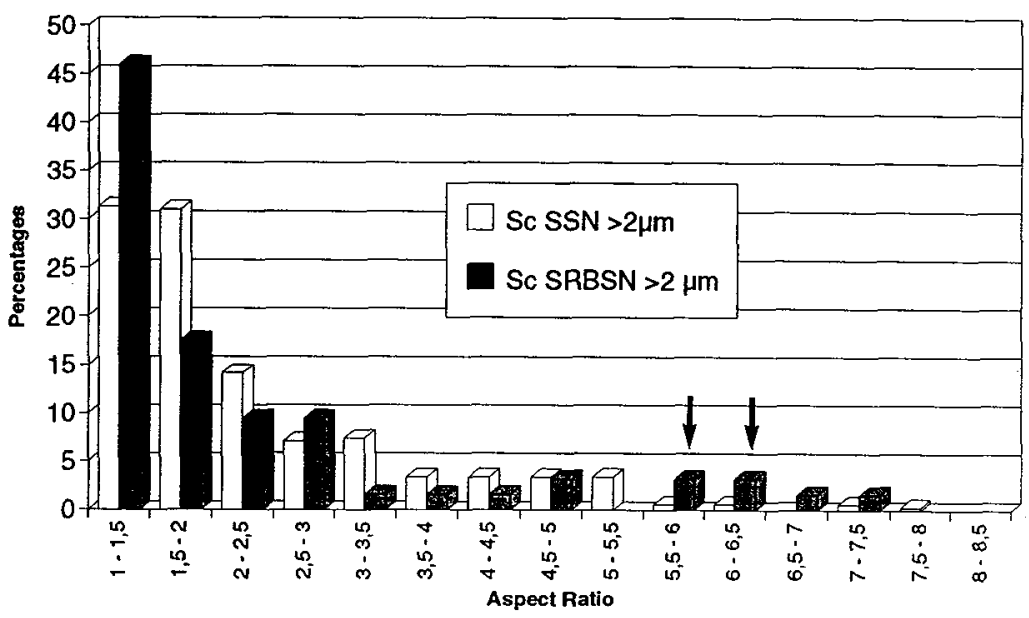

Fig. 4 Aspect-ratio distributions of SSN and SRBSN doped with $5 \mathrm{wt} \% \mathrm{Sc}_{2} \mathrm{O}_{3}$. Note that only the large grain fraction $>2 \mu$ grain diameter is shown. 
The results presented show that kinetic and diffusion controlled processes strongly affect grain morphology. Moreover, interface chemistry in combination with residual glass viscosity (and diffusion path) influence the aspect-ratio and hence, resulting fracture toughness. It was shown that a high aspect ratio (in the large grain fraction) is necessary to support toughening mechanisms such as crack defection and crack bridging. Furthermore, it should be born in mind that the presence of continuous amorphous films along grain boundaries is a prerequisite for debonding to occur (small changes in interface structure and interface chemistry seem to have no noticeable effect).

\section{Conclusions}

Four different $\mathrm{Si}_{3} \mathrm{~N}_{4}$-based ceramics ( $\mathrm{SSN}$ and SRSBSN doped with 5 wt $\% \mathrm{Y}_{2} \mathrm{O}_{3}$ and $\mathrm{Sc}_{2} \mathrm{O}_{3}$ ) were investigated by dilatometry, quantitative microstructural analysis and additional SEM and TEM observations. SEM studies showed intergranular fracture mode for all materials, independent of additive composition. HREM and AEM observations revealed only minor differences in interface structure and chemistry. A continuous amorphous grain-boundary film is present covering all grains. Additive cations, apart from excess $\mathrm{O}$ and $\mathrm{N}$, were detected at the interface films. It is thought that debonding occurs along the interphase upon crack propagation. While the two yttria-containing materials as well as the $\mathrm{Sc}_{2} \mathrm{O}_{3}$-doped SRBSN showed no significant difference in both overall microstructure (grain-diameter and aspect-ratio distribution) and fracture resistance, the $\mathrm{Sc}_{2} \mathrm{O}_{3}$-doped $\mathrm{SSN}$ sample revealed a strong discrepancy in microstructure and fracture toughness (about $50 \%$ decrease). It could be shown that the observed deviations are mainly due to two effects: (i) change in grain morphology and (ii) influence of interface chemistry. A reduced aspect ratio of the large $\mathrm{Si}_{3} \mathrm{~N}_{4}$-grain fraction was found in $\mathrm{Sc}_{2} \mathrm{O}_{3^{-}}$ doped SSN, which resulted in the observed reduction in fracture toughness. Moreover, the difference in interface chemistry (lower glass viscosity for $\mathrm{Sc}_{2} \mathrm{O}_{3}$ addition) in combination with a prolonged sintering time (heat treatment) strongly affects kinetic controlled processes such as grain-boundary diffusion, which in turn resulted in the change in grain morphology as well as fracture resistance.

\section{Acknowledgement}

The authors would like to thank the Deutsche Forschungsgemeinschaft (DFG) for financial support.

\section{References}

[1] Becher P.F., J. Am. Ceram. Soc., 74 [2] (1991) 255-69.

[2] Evans A.G., J. Am Ceram. Soc., 73 [2] (1990) 187-206.

[3] Steinbrech R.W., J. Europ. Ceram. Soc., 10 (1992) 131-42.

[4] Kleebe H.-J., J. Europ. Ceram. Soc., 10 (1992) 151-59.

[5] Mitomo M., et al., J. Am. Ceram. Soc., 73 [8] (1990) 2441-45.

[6] Rödel J., J. Europ. Ceram. Soc., 10 (1992) 143-50.

[7] Mitomo M., Uenosono S., J. Am. Ceram. Soc., 75 [1] (1992) 103-108.

[8] Obenaus P., Herrmann M., Pract. Met., 27 (1990), 503-513

[9] Tredway W.K., Loehmann R.E., J. Am. Ceram. Soc., 68 [5] (1985) C131-C133.

[10] Kleebe H.-J., Hoffmann M.J., Rühle M., Z. Metallkd., 83 [8] (1992) 610-17. 